\title{
A community of practice or a working psychological group? Group dynamics in core and peripheral community participation
}

\author{
Abstract. The concept of communities of practice (CoP) has become increasingly influential in \\ management literature. Yet, many scholars regard the term as too homogenous and lacking in \\ empirical support. Our study explores the Silver Academy, a project involving over 100 \\ unemployed and self-employed managers over the age of 50, who came together with the \\ purpose of sharing knowledge and experience in starting up their own businesses. The study \\ shows how the Academy matches the notion of CoP including mutual relationships, shared \\ engagement and a common consensus of membership. However, applying Bion's (1961) theory \\ of groups, we challenge the homogenous and consensual notion of a community of practice, \\ illustrating how, through unconscious group processes, some group members exhibit work- \\ group mentality and the capacity for realistic hard work (and leadership), while others are \\ caught in a basic-assumption mentality, prone to feelings of anxiety, guilt and depression. This \\ is particularly so for a group that has gone through the recent trauma of unemployment.
}

\section{Keywords}

Communities of practice, CoP, group dynamics, group conflict, group psychodynamics, Bion Since its inception as a formulation of how knowledge is created and transferred (Brown and Duguid, 1991; Lave and Wenger, 1991; Wenger, 1998), the concept of communities of practice $(\mathrm{CoP})$ has become increasingly influential within the management literature and practice (Roberts, 2006). However, as Amin and Roberts (2008) warn, CoP has also become a homogenised term, glossing over significant variations of situated practice with very different outcomes. The residual problem is that the term 'community' lures the reader into the trap of seeing it in consensual terms of a helpful, bounded group. Cox (2005: 529) cautions that seeing CoPs as self-sufficient entities rather than sites of change and conflict is a 'critical failing'. As Hong and O (2009) also warn, the difficulties of collaborating with participants from diverse 
backgrounds and identities have been understated. Contu and Willmott (2003) also warn that the concept of community glosses over fractured, dynamic processes of formation and reproduction in which there can be schisms and precarious alignments. Empirical data, however, is lacking on the dynamics, conflicts and schisms within CoPs. The current study offers precisely such evidence, allowing us to redefine CoPs as groupings or networks of people who share interests and/or face similar problems and who support each other by trading information as well as knowledge, mainly in the form of stories. Far from stable and homogeneous, CoPs are fluid, have relatively open boundaries and involve interactions and alignments between core and peripheral members in which unconscious processes drive a dynamic interplay between conflict and consensus, trust and schism, inclusion and exclusion.

The focus of this article is the Silver Academy, a group of over 100 unemployed managers who had been brought together for the purpose of starting up their own businesses through knowledge-sharing and peer-to-peer critical feedback; and offering opportunities for doing business with each other through discovering synergies and cross-fertilization of ideas. The starting point for the study was whether this group of demoralized managers who had recently experienced traumatic redundancies from highly paid and prestigious jobs could function as a $\mathrm{CoP}$ - whether, in other words, they could function as a community not only supporting each other emotionally but sharing knowledge, skills and networks in radically restarting their lives outside the corporate world. We had an opportunity to observe closely the functioning of such a group, the Silver Academy, over a period of three years, highlighting how participants developed a shared outlook, a degree of consensus and powerful emotional relationships. However, as the group matured over this period, we were also able to observe much more complex dynamics in the relations among the participants, a gradual separation into core and peripheral members and the drifting of members in and out of the group. We also became aware that for some of its members the group primarily functioned as a support mechanism for starting 
new business ventures; these members engaged in realistic hard work and many succeeded in restarting their lives as independent entrepreneurs. Others, however, experienced the group more as a source of emotional support for dealing with personal problems. This support was not always effective or reliable and at times caused rifts and tensions in the group. This prompted us to draw on Bion's (1961) theory of group psychodynamics, questioning the homogenous and consensual conception of a community of practice and highlighting unconscious group processes. Under the influence of these processes, some group members exhibit work-group mentality and the capacity for work, while others are caught in a basic-assumption mentality, prone to feelings of anxiety, guilt and depression. Even when a community has specific aims, these can be hindered or furthered by the emotional drives of the sub-groups that it contains.

The study therefore makes three core contributions. Firstly, we help to clarify the definition of $\mathrm{CoP}$ by challenging current consensual notions, offering instead a dynamic model which incorporates both collaboration and conflict. Secondly, we address the specific question of whether and under what circumstances a group of unemployed managers and professionals can function as a CoP supporting each other in starting their own businesses. As a longitudinal study in contrast to the more commonly undertaken cross-sectional studies, this one reveals many of the intricate dynamics, fissures, splits and conflicts that tend to go unreported. Thirdly, the article offers a cross-fertilization between two bodies of literature that have tended to stay apart - the literature on communities of practice with its considerable insights on how knowledge and learning develop across professional groups and psychodynamic theory with its intimate understanding of group dynamics that may inhibit or promote knowledge sharing and learning.

In addressing these contributions, the study seeks to answer two research questions:

- Can individuals, scarred by the trauma of unemployment, collaborate in a CoP to restart their professional lives and launch new businesses? 
- What group processes and tensions are exhibited in this CoP, and with what results on the community, groups and individuals?

The rest of this article is divided into four parts. Firstly, we offer a brief critical overview of CoP literature over the last 20 years and introduce Bion's (1961) theoretical framework as a conceptual lens through which the understanding of the group dynamics of CoPs can be analysed. In Methodology, we describe the aims of the Silver Academy and explain the fieldwork on which this article is based. We then present the Findings of the fieldwork followed by Discussion in which we challenge the homogenous and consensual notion of a CoP and, through a cross-fertilization of CoP and psychodynamic theory, explain some of the intricacies of the group dynamics that characterized the Silver Academy since its inception.

\section{Communities of Practice - a practical concept?}

According to Wenger (1998) communities of practice are everywhere - at home, at work, at school - and most of us belong to several communities of practice at any given time. It is argued that what makes a $\mathrm{CoP}$ approach unique is that it brings together a group of people who are informally bound together by shared expertise and a passion for a joint endeavour, sharing their experience and knowledge in creative ways to solve problems (Wenger and Snyder, 2000). Like networks, CoPs comprise relationships, interactions and connections among participants, but unlike networks they have a focus on a substantive topic (Wenger, 1998). CoPs have been conceptualised from a wide array of perspectives, maybe reflecting the concept's preparadigmatic phase (Corso, Giacobbe and Martini, 2009). They have been called a notion (Duguid, 2005; Handley, Sturdy, Fincham and Clark, 2006); a node (Wenger, 1998); a general scientific perspective (Peltonen and Lamsa, 2006); an approach (Roberts, 2006); a concept (Pemberton, et al., 2007); a conceptual lens (Cox, 2005); a nexus (O’Donnell, Porter, McGuire, Garavan, Heffernan and McCleary, 2003); a collaborative strategy (Garavan, Carbery and Murphy, 2007); a potential theory of knowledge creation (Roberts, 2006); a virtual community 
of informal groups (Cox, 2005) and networks of employees doing similar work (Cross, Laseter, Parker and Velasquez, 2006). It is hard to disagree with Handley et al's (2006) comment that the term is ambiguous. Kerno (2008) also warns that it is imperative that CoPs be understood in terms of their limitations as well as their benefits, an analysis of the literature often presenting a 'rose-tinted' view of CoPs, with any negative aspects unspoken or under-researched (Pemberton et al., 2007).

The formation of a CoP depends on various conditions. Gilley and Kerno (2010) suggest that such communities are composed of functionally similar individuals who share a passion for a particular range of practices. Such individuals have a high degree of shared understandings, assumptions and repertoires - that is, they are cognitively close (Lindkvist, 2005). However, CoPs often emerge from existing research as 'emotionally anorexic' (Fineman, 1993: 3). A notable exception can be found in Korczynski's (2003: 73) work, who used the term 'communities of coping' to describe how call centre employees get through their stressful working day coping through informal but 'deeply important' collegial support. Whether Korczynski's call-centre employees working in highly regimented corporate environments would qualify as a $\mathrm{CoP}$ is debatable but the value of his research lies in reintroducing emotion and emotional labour to the study of occupational groups. Our own study of the Silver Academy revealed from its early stages some of the complex emotional patterns displayed in both face-toface and online interactions among its members and also some of the psychological defences deployed by members, sometimes individually and some times collectively, to cope with potentially threatening emotions. To understand these processes we turned to the theory of group dynamics, and particularly the role of unconscious processes within groups. As Stokes (1994) points out, the experience of working in a group can be powerful and even overwhelming as group members seek to balance the tension between group membership and independent identity. As Macpherson and Clark (2009) posit, participation in the group becomes dependent 
on the members' ability or willingness to negotiate and manage conflict. Hence, by examining the dynamics of these group processes, our study seeks to contribute to how the emotional health of CoPs can be nurtured and sustained.

Psychodynamics is a loosely defined term that describes the application of psychoanalytic concepts and theories and, in particular, the concepts of unconscious and psychological defence to group and organizational phenomena (Gabriel, 2008: 238). The term is associated mainly with the work of the Tavistock Institute whose approach was strongly influenced by the theories of Wilfred W. Bion, a decorated army officer in World War I, trained as a physician and subsequently as a psychoanalyst. Bion (1961) based his theory on an observation that groups only stay focused on a task some of the time. At other times, they appear to engage in activities that seem designed to stop them from working on the task. He described the first as work-group mentality ( $W$-mode), when group members are able to manage shared tensions, anxieties and relationships, in order to function effectively, showing a 'capacity for realistic hard work' (Bion, 1961: 157). In these circumstances other considerations, like group rivalries, tensions and emotional displays assume secondary significance and are subordinated to the urgency of addressing the task. Bion described the opposite tendency as basic-assumption mentality when a group is overwhelmed by strong emotions: anxiety, fear, hate, love, hope, anger, guilt and depression (Bion, 1961: 166). Under basic assumption mentality, group members lose sight of the task and generally lose contact with reality, withdrawing in a fantasy world of imaginary threats and opportunities. A casual observer may have the impression that the group is working effectively, yet in reality the group has lost its ability to interact with the outside world, to test ideas against the evidence and to act rationally (Gabriel, 1999: 119).

Bion distinguishes three basic assumptions - in other words collective fantasies where a group behaves as if something unspoken and unconscious can be taken for granted. In basic assumption dependency (baD) a group places its faith on an omnipotent and omniscient leader 
who may be formal or informal, expecting him/her to deliver success; members lapse into passivity and inaction. In basic assumption flight-fight (baF/F) groups make an impulsive decision to fight or to flee from an imaginary danger, while realistic threats confronting the group go unnoticed. Frequently such groups scapegoat one of their members on whom they place the blame for all their troubles, most commonly on a failed leader or a free-rider. Finally, in basic assumption pairing (baP) a group indulges in the fantasy that the coming together of two people, two ideas or even two organizations will bring about a new beginning for the group or even generate a messiah who will lead them to the promised land. The emotional tone of each basic assumption is distinct - baD is characterized by obsequious loyalty and love for the leader, $\mathrm{baF} / \mathrm{F}$ by extreme anger or fear, and baP by blissful hopefulness.

What has made his theory enduring and illuminating has been its ability to account for the fragility and intensity of group dynamics, for a group's ability to precipitate fundamental changes in the mental functioning of its members and for the critical role played by the management and containment of anxiety in a group's functioning. These are all areas in which subsequent theorists were able to build upon (e.g Turquet, 1974; Simpson, 1997; Parker, 1997).

Bion's theory of group dynamics seems to lend itself particularly well to the study of a CoP, like the Silver Academy, whose original purpose was to help its members cope with the financial and psychological damages of job loss. Like Bion's army personnel in his original Northfield experiments though of course not to the same degree, the members of the Silver Academy were traumatized and demoralized, maybe not due to enemy action, but due to the vagaries of the job market and large scale socio-economic changes over which they had little control. Like Bion's subjects, they faced a collective enemy, that of sinking into dejection, depression and inactivity. And like Bion's subjects, by incorporating themselves in a group of people facing the same predicament they were offered an opportunity to make a fresh start in their individual lives, rediscovering their self-confidence and self-respect. 


\section{Methodology}

\section{Research Aims and Context}

In their study of unemployed managers, Gabriel, Gray and Goregaokar $(2013,2010)$ note that several years after being 'terminated' the scars of job loss remain. As Gray, Gabriel, and Goregaokar (2015) also note, the reaction of unemployed professionals to helping interventions such as executive coaching are variable, ranging from supportive to cool and at worst dismissive. For many unemployed professionals, encountering a researcher, academic or coach seemed to exacerbate their plight, drawing feelings of anxiety, shame, envy and anger which could be hard to contain. The aim of the Silver Academy programme, described next, was to explore whether and how such a group could be brought together within a process of mutual support, collegiality and learning. In other words, could a disparate set of unemployed managers constitute itself as a CoP?

The Silver Academy, funded by the EU's Interreg IVC People Project, was delivered under the auspices of a university located in the south-east of England. Through the project, 112 unemployed managers, over the age of 50, were recruited, the main entry requirements being that they had been unemployed for a minimum of six months or were on notice of being made redundant; they all expressed a strong commitment to start their own business or were already owning dormant or failing businesses. With the opportunity for external funding from the European Union, we were interested to see if a group of unemployed managers, in similar circumstances, could be helped towards fulfilling ambitious goals: entrepreneurship and business start-ups. In addition to emotional support, other goals included providing opportunities for knowledge-sharing and peer-to-peer critical feedback; and offering opportunities for doing business with each other through discovering synergies and crossfertilization of ideas. 
At the start of the programme, $56 \%$ of the delegates were unemployed, $28 \%$ were facing redundancy and 16\% were already self-employed and looking for support to achieve success in their business. Of the 112 recruited to the programme, 77 attended four or more of the seven scheduled workshops over a period of five months. By the same token, 36 attended three or fewer events, some dropping out immediately, others attending intermittently. Hence, there was a steady tail-off of participation over the 5-month duration of the Academy.

However, members of the Academy set up an Internet forum that has remained active for three years after the end of the funding and a core of some 20 or 30 members have continued to meet regularly to provide support and advice to each other. At the end of the funded programme, 20 new businesses had been founded against an original target of 10, and 13 of 16 originally stagnating or dormant businesses had been turned around. The Academy, then, can claim a considerable degree of success at this level, against which must be reckoned the disappearance of numerous delegates along the way. According to some estimates, $20 \%$ of the original recruits were unsuitable to participate either due to lack of fundamental business skills or due to severe mental health problems. The Academy also attracted: 'Inveterate group goers. They were aimless, but it was free.' (Sally, Academy administrator).

From the beginning, programme facilitators made it clear that this was not a training programme, training being the transmission of explicit, abstract knowledge from the head of someone who knows to the head of someone who does not (Brown and Duguid, 1991). Hence, epistemologically, the programme was aligned with the philosophical spirit of CoPs, seeing knowledge acquisition as socially situated and actively created by individuals themselves (Lave and Wenger, 1991). The learning process was characterised to participants as a mentoring toolkit, comprising: one-to-one mentoring, scheduled networking sessions, peer-to-peer "club" sessions, virtual boardrooms (action learning sets) and online delivery, interspersed with short content input from external experts, when required (the themes being chosen by the delegates). 
The attempt to actively empower participants to take control of their own learning was largely responsible for some delegates deciding to organise their own 'satellite' seminars between Academy workshops around themes they wanted covered in more depth. These workshops were facilitated by Academy members who were experts in their field and included marketing and the uses of social media for business growth. Another participant initiative was the launching of a Silver Academy social media website, (an example of practice in a congealed form: Wenger, 1998) through which participants communicated with each other between workshops, debated issues and shared resources.

\section{Research Design and Data Analysis}

The qualitative research design for this study was exploratory, and flexible, involving a reflexive process at each stage (Hammersley and Atkinson, 2007). Hence, while we began with a set of research questions, conceptual framework and methods, these were emergent rather than fixed at the start of the study. Sampling design, for example, including the number of participants planned for interview was not predetermined, the interviews ceasing once data saturation had been reached. The sampling design comprised theoretical sampling, an approach where people, organizations, events or incidents are taken on the basis that they may help to develop theoretical constructs (Gray, 2017). The sample size of 22 qualitative interviews was not so large as to make the attraction of rich, thick data problematic (Onwuegbuzie and Leech, 2007), nor too small, so that it becomes difficult to achieve data saturation (Flick, 2006).

At the end of the seven month long programme, the research design comprised a two stage, longitudinal study. Stage 1, which occurred immediately after the completion of the programme, consisted of qualitative data gathering using two focus groups of Academy members (a volunteer sample) and in-depth qualitative interviews with 22 members chosen from the focus groups. In selecting this sample, an intensity sampling approach was adopted (Gray, 2017), that is, the selection of information-rich cases that were capable of providing detailed 
information such as the illuminating quality of their learning experiences, their challenges and changes in identity and their emotional journeys.

The focus groups and interviews addressed themes such as the extent of their business progress, sources the Academy had provided for their learning, the role of networks within the Academy, eureka moments triggered by interactions, limitations (personal and collective) and promising beginnings and hopes that became dashed. Examples of questions included: (1) If your business journey was like climbing a mountain, what does the peek look like from where you are now? To be higher than you are now, what should you have done differently? (2) What has been your contribution to others in the network and satellite events? How has that contribution helped you personally? In Stage 2, three years after the end of the programme, the Academy LinkedIn group was contacted and asked to participate in a focus group. Membership of this social media site was taken as a proxy for continuing interest in the aims and aspirations of the Silver Academy, particularly the activity of business building. Questions explored what had happened to their businesses since the end of the Academy and probed the dynamics of the Academy with questions such as: If you had to think of the SA in terms of a metaphor, for example that it is like a machine, or like a family, or like a club of professionals, what metaphor do you think may capture the chief qualities of the SA from where you stand? With the permission of respondents, all focus groups and interviews were audio recorded and transcribed for data analysis. The two researchers also took notes that sought to capture reflective observations on the dynamics taking place within the group session, an example of what Patton (2015) terms becoming sensitized and conscious of the context, and alerting us to look for specific content as we undertook the interviews.

The unit of analysis was the group itself, investigating the dynamics, achievements, emotions and tensions amongst these unemployed, aspiring entrepreneurs. The research sought to capture and articulate as many 'voices' of CoP members as possible, in order to capture how different 
participants experienced the Silver Academy, whether in emotional, instrumental or other terms. Multiple voicing seeks out respondents with wide ranging views on a matter and includes these views without pressing them into coherence (Denzin and Lincoln, 2003). Our research also adopted a narrative methodology (Creswell and Maietta, 2002) in which researchers elicit stories and probe for the meaning of experience through a process of creative "restorying ... the process of gathering stories, analyzing them for key elements of the story (e.g., time, place, plot, and scene), and then rewriting the stories to place them within a chronological sequence" (Creswell, 2003: 14). Note that all names below have been changed to protect anonymity.

Data analysis was conducted using thematic analysis, an approach for identifying and analysing patterns (themes) within qualitative data (Braun and Clarke, 2006). This can include a hybrid approach using theory-driven codes from the literature and data-driven codes arising inductively from the data (Fereday and Muir-Cochrane, 2006). We firstly familiarised ourselves with the data through reading and re-reading the transcripts before generating an initial set of sub-codes. If appropriate, sub-codes were assigned to one of the theory-driven codes; but where the theme appeared outside this pattern a new, data-driven code was generated. Through an iterative processes, data-driven codes were refined and sometimes merged to create more substantive, over-arching descriptions of the data. Hence, in seeking to show evidence that the Silver Academy was a community of practice, themes from the CoP literature such as 'sustained mutual relationships: harmonious or conflictual' and 'shared ways of engaging' were coded. But new themes also emerged inductively from the data analysis process such as 'self confidence', 'personal transformational change' and 'negative features of the community'. A total of 10 theme-driven codes were applied with 15 data-drive codes, following what Pratt 
(2009) advises as the need to demonstrate a chain of evidence showing how the analysis moved from data to interpretations ${ }^{1}$.

\section{Findings}

In this section we draw upon the data to address the questions of whether individuals, scarred by the experience of unemployment, can work together, exploring for evidence for both working group and basic assumption mentality. We contiguously address the features of CoP (from the literature - presented in italics), exploring the interplay between theory and data in order to assess whether and how CoPs can display similar group dynamics as more conventional groups.

\section{Work-group mentality within a community of practice}

Work-group mentality tests itself against reality, where new ideas demand development and action (Armstrong, 2010) - in the case of the Silver Academy personal development necessary for the realization of a new business idea. This was the fundamental idea that kept the Academy together. In achieving this a strong consensus of membership developed within the Silver Academy, in that members saw others as people in the same position as themselves, that is, people who were driven by a strong desire to start their own business. In a similar way that individuals in therapy groups, observed by Bion, approached the overcoming of their individual mental disorders as part of a task for the whole group, individuals in the Silver Academy saw the success of their individual business ideas as part of a task for the entire group. There was a willingness to share information and to celebrate the success of others. Excessive criticism was pushed away to develop a somewhat unanimous shield to defend the group's identity (observational notes).

As researchers, we observed discussions of Academy members during their four-weekly meetings over six months, and also during the focus groups we conducted. We also followed the

\footnotetext{
${ }^{1}$ Audit trail with examples of a theory-driven and data-driven codes and sub-codes available from authors on request.
} 
intensive on-line communication among members of the Academy over this period. During these interactions, there were occasions when the Academy functioned like a well-drilled team, going about accomplishing a task without avoiding obstacles and objections, listening attentively to each other's ideas, overcoming difficulties and considering problems of implementation, funding and marketing. On these occasions when the Academy functioned in a work-group mentality, it was palpable that, whatever misgivings they may have had, participants maintained a positive but critical attitude on the task faced, a task that absorbed all their attention and creativity.

What factors assisted Academy members in attaining a work-group mentality? The fact that they were all of a similar age was 'quite helpful' (Nancy). They were all of 'a level and a quality of intellect' (Focus group delegate). Members were 'of a level of expertise, of professionalism, of seniority and I think that made a big difference' (John). The common consensus of membership contributed to the rapid flow of information and ideas. Several participants talked of 'light bulb moments' (Christine), or 'mini eureka moments' (John), allowing members to move swiftly through development stages for their ideas (Alice). As Bion (1961: 89) asserts, in work group mode, individuals are 'hopelessly committed' to the development of the group as a whole.

There was sufficient expertise within the Academy that problems encountered by one member could be swiftly and directly addressed by another with a minimal need for background information. 'There was another guy in the group who had a very strong marketing background ... and he was really quite blunt, ... and said to this guy, 'Don't go there- don't- don't even bother' he said, 'look, these are the reasons you shouldn't' - now I think the guy still wasn't convinced but I thought he's had the message, if he's heard it and listened, it's going to help him' (Janice). This professional knowledge, knowing what others know and tacitly acknowledging others' competencies and strengths, became widely understood, particularly in terms of identifying members with vital expertise. Particularly important here were members with 
expertise in sales and marketing, one of whom ran a series of 'satellite' Academy events on a Saturday. Other delegates were brought in to design Academy members' websites. This focus on action and the achievement of specific tasks is one reason that Bion (1961) refers to the work group as the sophisticated group.

The common tool used by Silver Academy delegates was the power of insightful questioning (Revans, 1982), demonstrating the ability of delegates to assess the appropriateness of actions and products. 'I came to the Silver Academy expecting to be sort of ... told what to do. I found out that that's not the case at all, I'm not being told what to do' (Focus group delegate). Delegates had to make their own decisions but these were based around 'the tools and information through their questioning that enabled me to do that (Focus group delegate). Through the Silver Academy process a shared discourse and common viewpoint regarding the external 'lay of the land' was developed, with delegates feeling 'much more confident about giving information, partly because, you know, we've built up a rapport with each other' (Christine). In terms of shared ways of engaging in doing things together, delegates could just be themselves in a non-competitive atmosphere that included sharing in each other's successes. In virtual boardroom meetings business ideas were challenged, affirmed and supported. 'Everyone was saying, wow, that's a great idea, that should work and diddle dah, and some people were forthcoming with contact information and organisations which I could work with' (Jim). When in work group mode, the group becomes a powerful force, developing a virtual life of its own, generated by the ideas and beliefs its members bring to it (Bion, 1961).

Despite the brevity of the programme (seven workshops over a period of six months), there was a strong sense of sustained mutual relationships based upon acceptance, although, as we shall see, work assumptions could quickly become swamped by basic assumptions when anxieties got too high (Fraher, 2007). 'They just accept me as I am' (Focus group delegate), while some mused on what made the Silver Academy such a supportive, positive experience in which 
people 'pulled together'. For many, trust and rapport developed quickly, 'which is why the Silver Academy worked well, that we're not in competition and we are able to be critical and to critique each other's ideas (Focus group delegate). This trust was, in part, based upon the recognition of each other's expertise: 'some of those were very, very, strong business people, not that I knew them terribly well, perhaps I sort of liked them, and I was having to learn to trust them' (Frank.) As a result, delegates were sometimes able to develop deep relationships in which emotions sometimes bubbled to the surface. 'When we were doing mentoring one of the guys started to cry on my shoulder because I sort of got to the crux with something that had been trying him, so that was quite moving.' (Jim).

Within the Silver Academy, members developed mutually defining identities, partly because they were at similar stages of business start-up. As one delegate put it: 'I came away with a clear view of who I am. I left that day interrogating myself, saying 'What's stopping me?' and I honed it down to my mind set.' (Alice). Another delegate who had previously felt that job loss had turned her into a victim status, within two months of joining the Silver Academy said: 'It was like the scales fell from my eyes and I saw how my life wasn't over' (Focus group delegate). Overall then the Academy provided those delegates who remained at its core with the support and reinforcement they needed in order to maintain their identities in the face of adversity as competent professionals. Work group mode is consistent with increasing and developing the ability of each individual to develop their skills in pursuit of their goals. (Bion, 1961). But while learning and identity support were essential consequences of the Academy's group dynamics, what provided its fundamental purpose was a firm focus on the part of each member on the task of starting a new business and setting up as an independent professional.

Practical help with starting a business as well as identity support and reinforcement accounts for the endurance of the Academy beyond its official, funded end. Thus, independently of the original organisers, a group of members organised their own management group, established a 
LinkedIn social media site and pledged to meet every two months. Three years on, these bimonthly meetings (typically drawing between 6 and 12 attendees) kept going and Academy membership has grown to 225 members, paying an annual subscription of $£ 50$. For the original members, life and business has had its 'ups and downs', often triggered by difficult trading conditions. Some have had health scares. But many of the lessons of the Academy, have endured, including the need to reshape plans in the face of adversity and to be open to feedback from others, benefitting from the 'generosity of ideas from people - because it's the people and the content and the encouragement' (Peter).

In conclusion, then, there was ample evidence of work group mentality for a substantial part of the Academy's functioning, similar to that observed by Bion. This was in spite of, first, the fundamentally different nature of the task facing the Academy's members compared to that of Bion's therapeutic groups, and second, the far looser association prevailing in the Academy as a $\mathrm{CoP}$ as against Bion's intensive therapeutic groups. As with the groups observed by Bion, emotional support, learning and identity reinforcement were important outcomes of the group process in work group mentality but did not define the task which was firmly identified with the setting up of new business ventures.

\section{Basic assumption mentality within a community of practice}

Our findings offer some evidence of basic assumption mentality in the functioning of the Silver Academy. This occurs when, fuelled by anxiety and unconscious fantasies, groups lose track of their task and swing towards a more defensive state (Fraher, 2007). As Armstrong (2010: 148) notes, this can occur when people are 'wrestling with the challenges and fears, both for survival and identity, aroused by the nature and pace of change'. Diagnosing a group as having lapsed into dysfunctional mental functioning is not easy. Researchers may project their own preconceived ideas onto the phenomena they are observing, in a similar way that a therapist may sometimes impose his/her version of reality on a patient. All the same, we cannot avoid making 
some interpretations and seeking to corroborate them as best we can. How? First, by identifying different features of a situation all of which support a particular interpretation. Secondly, by comparing our notes as researchers and playing devil's advocate with each other's interpretations. Thirdly, by considering alternative or maybe simpler way of interpreting a particular group behavior and eliminating such possibilities. Fourth, by noting the results of group process and noting whether a particular group discussion led to any material outcomes or whether it functioned to express powerful emotions. In particular, we observed how the Academy members managed their anxieties individually and collectively, and the extent to which they sought to maintain control over potentially delusional positive and negative fantasies.

As we noted earlier, given their unemployed status, some members of the Silver Academy were in a fragile emotional state and found it hard to manage their anxieties and focus on the task. 'You want to help them, but when someone's in that space it's really hard to lift them.' (Jim). Individuals who found it hard to overcome their emotional distress and focus on the task were eventually shunned - 'I had the choice not to spend time with them' (Eric) - and some of them 'disappeared' (Frank). If in work mode there is a compulsion to develop, in basic assumption mode there is a regressive pull which seeks to evade the mental burden that development implies, particularly learning from experience (Armstrong, 2010). In basic assumption dependency $(\mathrm{BaD})$, the role of the leader is to quell the group's anxieties at the cost of losing focus in the task (Stokes, 1994), in the case of the Silver Academy, supporting each other in successfully setting up their business ventures. Some Academy members demonstrated dependency tendencies by approaching it as a 'course' through which they would magically be taught 'the answers' by experts. This perspective led to disappointment and rejection of the programme. 
'Those that were ready, willing and able to take the opportunity we were offering were able to understand the SA and felt empowered and excited to make the most of it....Then there were those that were not ready to take responsibility for their own future... These participants made excuses, blamed the course, got even angrier, had their fears confirmed and found ways to justify themselves and their decisions. These invariably dropped out.' (Harry, Academy facilitator).

The essential aim of basic assumption dependency is to attain security through the protection of an all-knowing and all-powerful individual (leader). The members act as if they know nothing and that the leader (in this case the facilitator) is omnipotent, or as we noted in one of the focus groups, the facilitator was seen as 'the good mother figure' (observational notes). If they wait long enough, the wise leader will come forth with a magic cure (Rioch, 1970). When the leader of a group fails to meet expectations (which they are bound to do), the group searches for an alternative, in this case Barry, who organised the satellite events where they could 'snuggle up to each other like little birds in a nest' (Rioch, 1970: 60). What is instructive about the effects of basic assumption dependency on the functioning of the Silver Academy is that it was firmly resisted by its more active members. Instead of seizing the group mind, dependency was contained and neutralized by the group itself, although those participants who were firmly locked in this mentality gradually withdrew and exited.

In basic assumption fight-flight $(\mathrm{BaF})$, the assumption is that the group can only preserve itself by fighting someone or something or running away from it. There was some evidence of this in the Silver Academy, usually taking the form of intolerance of late-comers, non-contributors, absentees or those seen as unsusceptible to the ideas of others. This is suggested in comments about delegates "sitting with arms folded and looking out of the window" (Mel) or about the group being a 'glorified soup kitchen, where everybody goes along, they sort of chat and, you know, exchange ideas and after an hour or so the go away but what have they actually got out of 
it?' (Raj). At times, ideas could be forcefully challenged and individuals felt insulted or even scapegoated. 'You had the pack mentality, they were onto you' (Frank) and you could be told 'the error of your ways' (Jim). There would also be some effort to encourage participants to make a contribution. But if it were felt their inaction was impeding the cohesion and progress of the group (and this would be quickly noted) they would be side lined. 'I didn't go out of my way to spend time with that person' (Bob). Some group members became particularly critical of those who seemed to display fixed ideas who could, as a result, become marginalised, illustrating that individual group members are often in different modes of group process, some in work mode and some in $b a$ at any one time (Higgin and Bridger, 1965). As with BaD, fighting and ostracizing tendencies was contained and neutralized by the more active group core, even if this meant that some participants eventually withdrew and left the Academy.

In groups seized by basic assumption mentality, the continuation of the group can become an end in itself, as members' relationship to the group overshadows their commitment to the task (Stokes, 1994). We noted earlier that a core of members continued to communicate via a LinkedIn Silver Academy group, and, three years after the end of the funded programme met occasionally. It is possible that basic-assumption mentality will eventually take precedence over work mentality even for this core group, with some of the successful members having little need for it and the unsuccessful ones drifting away in dejection and fatalism. Indeed, some members report that, the Academy may have already lost its way: 'For the moment there is no purpose' (Geraldine). Instead of being drawn together to support the practice of its members, the Academy may now have reached the point of becoming a waning community with very little practice to hold it together.

\section{Discussion}

Our study of the Silver Academy supports some of the features that define a community of practice as described by Wenger $(2011,1998)$, Wenger and Snyder (2000), Wenger, McDermott 
and Snyder, (2002) and others, as a group of people, informally bound together by a common domain of expertise, sharing experiences and knowledge in creative ways to solve problems (in our study business start-ups). Like Swan et al. (2002) the practices of constructing a community hinged on networking and knowledge brokering, often paying attention to the 'signature skills' of participants who possessed deep knowledge of specific themes (Contu, 2014: 289). But one of the semantic challenges posed by the term 'community' is its ambiguity and its application to group-based dynamics that are diverse and complex, with the notion of community itself, often naively rose-tinted. As Dempsey (2010) points out, one of the problems with the concept of community is that it is treated in the abstract and as a unified experience, ignoring critical differences based around class, race and sexuality and, even more importantly as we will discuss below, overlooking group dynamics. While Wenger et al. (2002) do warn against seeing communities of practice in purely consensual terms, their very use of the term 'community' can be seen as too laden with meaning, luring the reader into a trap (Cox, 2005). As we have seen, there were tensions within the Academy, one result of which was that more peripheral delegates voted with their feet. Significantly, at least in the first phase of data gathering, not one Silver Academy member experienced or referred to the Academy as a community, preferring instead terms such as 'a forum', 'think tank', self-help group', 'support network', 'a finishing school' or 'a university'. Three years later, looking back on the original Academy, only one member referred to it as a 'community of interest' (Barry).

The term 'community' originating in Ferdinand Tönnies (1887/1963) distinction between gemeischaft (community) and gesellschaft (society) evokes too uniform, traditional, cohesive and non-instrumental a social entity to spontaneously describe the mostly transitional, diverse, loosely bound and instrumental group of people who participated in the Silver Academy. Some theorists have acknowledged heterogeneity as an element of community, and note that communities may be defined as much by whom they exclude as whom they include (Young, 
1986). Indeed, the Silver Academy displayed strong tendencies to exclude or marginalize some members, notably those regarded as seeking to take without contributing and those seen as depressed or exhibiting mental health problems. As we noted earlier (Gabriel et al., 2013, 2010; Gray, et al., 2015), job loss can induce a sense of fragility in managers, so that the presence of troubled or less engaged individuals in a group becomes a source of great anxiety and frustration for the others who may opt to shun or exclude them.

In contrast to Gilley and Kurno's (2010) view that groups should be composed of functionally similar individuals, we found that the diverse areas of expertise (in sales and marketing, retail, accounting, and social media, to name but a few) was a key asset of the Silver Academy and a dominant reason that drew its members together, by offering each a broad spectrum of knowledge from the others. By contrast, other forms of diversity tended to introduce tensions. Thus gender, for example, prompted anxieties among female participants regarding men being too keen to dominate discussions or seeking unsolicited intimacy with unwanted compliments.

Commitment to practice and highly developed professional knowledge (which they were willing to share with the group) were keys to attaining central rather than peripheral participation in the group. Those who lurked within the group (for example, by failing to ask questions or offer advice), or who failed to take action (for example, deciding on their business idea or planning to set up a website), were marginalized. Even lurkers, as noted by Ross (2007), can sometimes profit parasitically when core members shared tips or expertise. What differentiated between the central and peripheral groups was that the former accepted and sustained the core ethos of the Academy, based on mutual support and peer-to-peer learning in pursuit of the task; in contrast, the peripheral group demanded (often publically in the plenary sessions) a simple 'cookbook' of solutions on how to start a business based on didactic training methods.

The major finding of our study concerns the group dynamics that characterized the relations among members of the Silver Academy, a dimension that tends to be disregarded by most 
commentators on communities of practice. Instead of a uniform community of people calmly sharing, trading and developing together, the Academy was a volatile, intense, emotional, and at times conflict-riven group with various emotional tendencies fighting it out for predominance. Overwhelmed by such emotions, this group can be experienced, in the words of one Academy participant, as 'a group of lost souls'. More generally, various destructive fantasies ('We are doomed to failure', 'Nobody appreciates $m y$ contribution') take over the group's mental functioning and totally neutralize its ability to deliver any concrete work or results. The result is that the group becomes separated from its purpose and its members get caught up in unconscious collusion, the outcome of which is stagnation and paralysis. In dependency mode, members turn to an external person (leader) expecting him or her to meet all the material and emotional needs of the group. As Burka, Sarnet and St John (2007) show, in this basicassumption mentality, members act as if they know nothing, cannot understand complexity and expect the omniscient and omnipotent leader to solve their problems. In contrast, the leader is overwhelmed by the burden of providing solutions to totally passive followers.

The basic-assumption mentality is rooted in resistance to development, 'a hatred of having to learn by experience at all, and lack of faith in the worth of such a kind of learning' (Bion, 1961: 89), epitomized in the Academy by a resistance to group work and a vocalisation from some participants that the 'secrets' of business start-ups should be simply revealed to them. This reflects a primitive state of uncertainty and fear (Burka et al., 2007) and represents what Anzieu (1975: 159) describes as 'a bewitching self-destructive illusion', the belief that if only one could learn the 'secret of success', then success is guaranteed. Thus, in line with Bion's (1961) dependence assumption, the leader (in this case, the Silver Academy facilitator or, at times, a seemingly very confident and knowledgeable individual) emerges as a kind of group deity 'one who [knows] the answers without need to resort to work' (Bion, 1961: 147-148). In this way, 
the knowledge of a small number of delegates who were regarded as experts in certain fields came to be venerated by the others who lapsed into a dependency mentality.

This analysis calls into question the 'seductive character of community' (Duguid, 2005:109 original emphasis) over and above that of practice. It is practice that draws CoPs together, constituting the social locus in which the community is sustained and reproduced over time (Duguid, 2005). Practice is critical to any analysis of communities of practice, a theme that accords fully with Bion's emphasis on the work group mentality ( $W$-mode) as the sine qua non of effective group functioning. By focusing on the task rather than seeking to defend themselves against overpowering emotions groups can develop their abilities to learn and to grow. For our unemployed Silver Academy delegates, however, the task involved a crucial ambiguity. At one level, they were brought together to pursue the collective task of fighting the dejection and trauma of job loss. At another level, however, they were each pursuing an individual task of launching their own business start-up using the expertise available within the Academy. For some, being members of the Academy provided 'a unique eureka moment'. For others, however, developmental moments were overshadowed by frustrations as work-group mentality was overtaken by basic-assumption mentality and the group labored with its demons rather than the task at hand.

Work-group dynamics resulted in different levels of participation (Roberts, 2006). In Lave and Wenger's (1991) study, new apprentices move from the periphery to full participation as they learn from the knowledge of skilled practitioners. Members who have full participation are more likely to wield more power in the negotiation of meaning (Roberts, 2006). Our study suggests a more turbulent and dynamic process where centripetal and centrifugal forces compete for ascendancy, as do work group and basic assumption mentalities. As French and Simpson (2010) have strongly argued, the two mentalities find ways of co-existing within the same group. In the early stages of the Silver Academy, some delegates felt isolated for a variety of 
reasons but persevered and eventually moved to the Academy's core; others drifted away or left altogether. As Sutherland (1985) comments, work-group activity is what ultimately takes precedence - individual moments of doubt and despondency are overcome with the support of the group when participants feel that they are motivated to perform useful work. This challenges Lave and Wenger's (1991) notion of centripetal movement from the periphery towards the centre, from novice to master. Some among our participants never made this transition, some stayed in the periphery and some drifted out of the Academy altogether.

\section{Conclusions}

In writing this article, we accepted Bion's (1978: 23) invitation to join him in 'the exercise of disciplined curiosity' about group behaviour. In particular, we sought to understand whether and how a group of demoralized and traumatized professionals and managers could constitute themselves as a community of practice, sharing knowledge and skills and supporting each other in restarting their stalled careers. Our fieldwork suggested that at least for a core membership, the Academy functioned in this manner. Our findings, however, also highlighted the vital importance of emotional dynamics in the functioning of communities of practice, most especially in the gradual separation between core and peripheral membership. Core members maintained a fairly strong focus on the task facing them, namely confronting the trauma of job loss by seeking to establish themselves as independent business people. Peripheral members, on the other hand, tended to vacillate between work-group and basic-assumption mentalities, now focusing on the task and now being overwhelmed by anxieties and fears. Work-group and basic-assumption mentalities, of course are not dichotomous, groups exhibiting both conditions at any one time. But one tends to dominate, and we have shown that the Academy's core, for a while at least managed to 'get work done', whilst other individuals remained peripheral or quit the programme. Our evidence suggests that the very segmentation of the Academy into core and periphery served defensive purposes, inoculating the core from basic assumption mentality. 
It also created a liminal zone for the periphery, one from which individuals could either drift away without their disappearance leading to a demoralization for the rest or, in rarer cases, be re-admitted to the core and participate in useful work. Hence, while collaborative activities are central to the functioning of CoPs in building reciprocity and trust amongst stakeholders (Pattinson, Preece and Dawson, 2016), our research revealed that collaboration can also be punctured by frustrations and schisms.

Our findings showed that some delegates developed deep, mutually regarding relationships and trust based on their professional knowledge which they were able to share with each other. But these relationships were as much based around tensions, challenges and critique (of each other's ideas) as they were around fellowship in distress. Hence, we support the views of scholars such as Cox (2005) and Roberts (2006) who warn against seeing communities of practice purely in consensual terms. Indeed, when trapped in basic assumption mode, consensus may revolve around an unconscious pull to evade disagreements and conflicts. We therefore support the view that within the term community of practice, more emphasis needs to be accorded to practice (Brown and Duguid, 2001), including how it is constituted and negotiated without obliterating disagreements and conflicts. The above analysis, then, allows us to come to our own definition of a community of practice as a group that is informally bound together to share expertise and knowledge in creative ways, but in which unconscious processes may generate tensions and divisions that frustrate the practice of the group.

Scholars versed in the literature of group dynamics and Bion in particular may not find it surprising that the Silver Academy, made of people recovering from the trauma of unemployment and experiencing intense anxieties about their self-worth and their future, occasionally lapsed into basic assumption behaviour. What such scholars will recognize as a significant contribution of our paper is that even such a group, through a segmentation into core and periphery could inoculate the core from basic assumption mentality and enable them to 
perform productive work through which they recovered from trauma and restored their sense of self-worth. For this reason, we believe that our research has considerable value at a time of great dislocations in employment patterns, when automation and artificial intelligence will draw increasing numbers of people (including professionals and managers) to situations similar to those facing the members of the Silver Academy. Forming communities of practice aimed at sharing knowledge may be a first step towards discovering new meaningful work opportunities and restoring their careers. The success of such communities of practice, however, will depend on the extent to which they will manage to channel their energy and creativity to productive ends while managing collective and individual anxieties.

What are the implications of our study for the composition and constitution of communities of practice? We see the presence of diversity within communities as a strength offering a variety of professional insights. However, diversity can lead to tensions that need to be managed through expert facilitation that orchestrates contributions and respects differences. Consensus, far from signalling harmony, may act as a cover for the group's anxieties, negative destructive tendencies and a pull from work into basic assumptions. For these reasons, group dynamics and the workings of unconscious group processes need to be recognised as fundamental elements of community of practice processes.

In conducting this study we acknowledge a number of weaknesses. Firstly, the voices that have gained hegemony in our narrative are those who successfully made the journey from the margins to the centre of the Silver Academy community. These are the voices of work-group mentality who show themselves capable of managing their shared tensions within their relationships in order to function effectively. They demonstrate an ability to conduct 'realistic hard work' (Bion, 1961: 157), including sustaining the Academy three years after the end of its funding. However, the voices at the periphery in our study (those caught up in the emotions of anxiety, guilt and depression) are quieter and more marginalized, but no less important because 
they can point us to the shortcomings of community of practice processes. Secondly, we could have enriched the findings with a number of detailed case studies, following the successes or otherwise of individual Academy members and their businesses, noting how and in what tangible ways, Academy membership had facilitated their business journeys. Thirdly, given that the Silver Academy recruited independent individuals, its implications for businesses and organisations may be limited. Finally, we acknowledge the methodological challenges of researching group dynamics. One of the strengths of our research design was that it used within-methods triangulation (interviews and focus groups), as well as observing Academy sessions and the focus groups, where data were collected through note taking. However, Weingart (2015) recommends the video recording of observational sessions provided cameras are installed in unobtrusive places and with the informed consent of participants (Nell \& Westmeyer, 1996). Such observational methods allow for the investigation of interaction processes based on information that participants naturally emit (Klonik, et.al, 2016).

We make a number of recommendations for future research. Firstly, we believe that the application of action learning approaches to group facilitation contributed to the positive outcomes of the Academy. Future research might explore these techniques in other settings such as in health, education and business to see if they help communities of practice to emerge. Secondly, although the evidence in our study is limited, we believe that CoP researchers need to attune themselves to group dynamics to understand how conscious and unconscious processes come to impact on work (outcomes) but also the emotional life of groups. We believe that, in addition to the interviews and focus group undertaken as part of our study, future research should consider adopting a more emic, ethnographic approach including video recorded participant observation, seeking to understand the phenomena that reflect the knowledge and meanings that guide the life of cultural groups within their own environment. Thirdly, while Lave and Wenger (1991) take the collective as the unit of analysis, we believe that our own 
study demonstrates that the individual remains a unit worthy of exploration, showing how individual journeys and biographies are shaped and moulded through and within collective communication and action. Finally, our study demonstrates that it is indeed possible for individual trauma to be addressed through collective group processes. Groups, in spite of formidable tendencies to conflict and decomposition, have also got remarkable recuperative and therapeutic qualities. And this applies to communities of practice too.

\section{References}

Amin, A. and Roberts, J. (2008) 'Knowing in action: Beyond communities of practice'. Research Policy, 37, 353-369.

Anzieu D. (1984) The Group and the Unconscious, London: Routledge and Kegan Paul.

Armstrong, D. (2010) 'Bion's work group revisited'. In The groups book. Psychoanalytic group therapy: Principles and practice including the Groups Manual. The Tavistock Clinic Series. London: Karnac Books.

Anzieu, D. (1975) The group and the unconscious. London: Routledge Kegan Paul.

Bion, W.R. (1961) Experiences in Groups and Other Papers. London: Tavistock Publications.

Bion, W.R. (1978) Four discussions with W.R. Bion. Perthshire: Clunie Press.

Braun, V. and Clarke, V. (2006) 'Using thematic analysis in psychology', Qualitative Research in Psychology, 3(2): 77-101.

Brown, J.S. and Duguid, P. (1991) 'Organizational learning and communities of practice: towards a unified view of working, learning and innovation'. Organization Science, 2, 40-57.

Brown, J.S. and Duguid, P (2001) 'Knowledge and organization: a social-practice perspective'. Organization Science, 12(2), 198-213.

Burka, J.B., Sarnet, J.E. and St.John. (2007) 'Learning from experience in case conference: A Bionian approach to teaching and consulting.' International Journal of Psychoanalysis. 88(4) 981-1000.

Contu, A. (2014) 'On boundaries and difference: Communities of practice and power relations in creative work'. Management Learning, 45(3): 289-316.

Contu, A. and Willmott, H. (2003) 'Re-embedding Situatedness: The Importance of Power Relations in Learning Theory', Organization Science, 14(3): 283-296.

Corso, M., Giacobbe, A. and Martini, A. (2009) 'Designing and managing business communities of practice'. Journal of Knowledge Management, 13(3) 73-89. 
Cox, A. (2005) 'What are communities of practice? A comparative view of four seminal works.' Journal of Information Science, 31(6) 527-540.

Creswell JW. (2003) Research design: Qualitative, quantitative, and mixed approaches, London: Sage.

Creswell JW and Maietta RC. (2002) Qualitative Research. In: Miller DC and Salkind N, J (eds) In, Handbook of Research Design and Social Measurements. 6th ed. London: Sage.

Cross, R., Laseter, T., Parker, A., and Velasquez, G. (2006) 'Using social network analysis to improve communities of practice'. California Management Review, 49(1), 32-60.

Dempsey, S.E. (2010) 'Critiquing Community Engagement'. Management Communication Quarterly, 24(3), 359-390.

Denzin, N.K. and Lincoln, Y.S. (2003) The Landscape of Qualitative Research: Theories and Issues. Thousand Oaks, CA: Sage.

Duguid, P. (2005) 'The art of knowing': Social and tacit dimensions of knowledge and the limits of a community of practice'. The Information Society, 21, 109-118.

Fereday, J. and Muir-Cochrane, E. (2006) 'Demonstrating rigor using thematic analysis: A hybrid approach of inductive and deductive coding and theme development', International Journal of Qualitative Methods, 5(1): 80-92.

Fineman S. (1993) Organizations as Emotional Arenas. In: Fineman S (ed) Emotion in Organizations. London: Sage.

Flick, U. (2006) An Introduction to Qualitative Research. London: Sage.

Fraher, A. (2007) 'Collective Guilt as a Force for Change: A Concept Paper'. Socio-Analysis, 9: $1-18$.

French, R. B., \& Simpson, P. (2010). The 'work group': Redressing the balance in Bion's Experiences in Groups. Human Relations, 63(12): 1859-1878.

Gabriel Y. (1999) Organizations in depth: The psychoanalysis of organizations, London: Sage.

Gabriel Y. (2008) Organizing Words: A Thesaurus for Social and Organizational Studies, Oxford: Oxford University Press.

Gabriel, Y., Gray D.E. and Goregaokar, H. (2013) 'Job loss and its aftermath among managers and professionals: wounded, fragmented and flexible'. Work, Employment and Society, 27(1) 56-72.

Gabriel, Y., Gray D.E. and Goregaokar, H. (2010) 'Temporary Derailment or the End of the Line - Managers Coping with Unemployment at 50’ Organization Studies 31(12) 1687-1712

Garavan, T.N., Carbery, R., \& Murphy, E. (2007) 'Managing intentionally created communities of practice for knowledge sourcing across organizational boundaries: Insights on the role of the 
CoP manager. The Learning Organization: The International Journal of Knowledge and Organizational Learning Management, 14(1), 34-49.

Gilley, A. and Kerno, S. (2010) 'Groups, Teams and Communities of Practice: A Comparison'. Advances in Developing Human Resources, 12(1): 46-60.

Gray, D.E. (2017) Doing Research in the Business World, London: Sage.

Gray, D.E., Gabriel, Y. and Goregaokar, H. (2015) 'Coaching unemployed managers and professionals through the trauma of unemployment: Derailed or undaunted?' Management Learning. 46(3): 299-316.

Hammersley, M. and Atkinson, P. (2007) Ethnography: Principles in Practice, 3rd edn. London: Routledge.

Handley, K., Sturdy, A., Fincham, R., \& Clark, T. (2006) 'Within and beyond communities of practice: Making sense of learning through participation, identity and practice. Journal of Management Studies, 43(3), 641-653.

Higgin, G. and Bridger, H. (1965) 'Tavistock Pamphlet No 10: The Psychodynamics of an InterGroup Experience. London: Tavistock Publications.

Hong, J.F.L. and O, F.K.H. (2009) 'Conflicting Identities and Power Between Communities of Practice: The Case of IT Outsourcing'. Management Learning, 40(3) 311-326.

Kerno, S.J. (2008) 'Limitations of Communities of Practice', Journal of Leadership \& Organizational Studies, 15(1) 69-78.

Klonek, F.E., Quera, V., Burba, M. \& Kauffeld, S. (2016) 'Group Interactions and Time: Using Sequential Analysis to Study Group Dynamics in Project Meetings'. Group Dynamics: Theory, Research and Practice, 20(3): 209-222.

Korczynski , M. (2003) 'Communities of coping: Collective emotional labour in service work'. Organization, 10(1), 55-79.

Lave, J. and Wenger, E. (1991) Situated Learning: Legitimate Peripheral Participation. Cambridge: Cambridge University Press.

Lindkvist, L. (2005) 'Knowledge Communities and Knowledge Collectivities: A Typology of Knowledge Work in Groups'. Journal of Management Studies. 42(6) 1189-1210.

Macpherson, A. and Clark, B. (2009) 'Islands of Practice: Conflict and a Lack of 'Community' in Situated Learning', Management Learning, 40(5): 551-568.

Nell, V. and Westmeyer, H. (1996) 'The Role of Observational Methods in Assessment and Analysis of Behavior Interaction in Small Groups', European Journal of Psychological Assessment, 12(2): 89-102. 
O’Donnell, D., Porter, G., McGuire, D., Garavan, T.N. Heffernan, M., \& McCleary, P. (2003) 'Creating intellectual capital: A Habermasian community of practice $(\mathrm{CoP})$ introduction. Journal of European Industrial Training, 27, 80-87.

Onwuegbuzie, A.J. and Leech, N.L. (2007) 'Sampling designs in qualitative research: making the sampling process more public'. The Qualitative Report, 12(2) 238-54.

Parker, I. (1997) 'Group identity and individuality in times of crisis: Psychoanalytic reflections on social psychological knowledge'. Human Relations 50: 183-196.

Pattinson, S., Preece, D. and Dawson, P. (2016) 'In search of innovative capabilities of communities of practice: A systematic review and typology for future research'. Management Learning, 47(5): 506-524.

Patton, M.Q. (2015) Qualitative Research \& Education Methods. $4^{\text {th }}$ ed. Thousand Oaks, CA: Sage.

Peltonen, T., \& Lamsa, T. (2004) "'Communities of practice" and the social process of knowledge creation: Towards a new vocabulary for making sense of organizational learning'. Problems and Perspectives in Management, 4, 249-262.

Pemberton, J., Mavin, S., \& Stalker, B. (2007) 'Scratching beneath the surface of communities of (mal)practice. The Learning Organization: The International Journal of Knowledge and Organizational Learning Management, 14(1), 62-73.

Pratt, M.G. (2009) 'For the lack of a boilerplate: Tips on writing up (and reviewing) qualitative research, Academy of Management Journal, 52(5): 856-862.

Revans, R.W. (1982) 'What is Action Learning?' Journal of Management Development, 1(3) 64-75.

Rioch, M. (1970) 'The work of Wilfred Bion in Groups', Psychiatry, 33, 56-66.

Ross, D.A.R. (2007) 'Backstage with the Knowledge Boys and Girls: Goffman and Distributed Agency in an Organic Online Community’. Organization Studies, 28(03) 307-325.

Roberts, J. (2006) 'Limits to Communities of Practice'. Journal of Management Studies 43(3) 623-639.

Stokes, J. (1994) 'The unconscious at work in groups and teams: Contributions from the work of Wilfred Bion', in A. Obholzer, and V.Z. Roberts. The unconscious at work, London: Routledge. Pp. 19-27.

Sutherland, J.D. (1985) 'Bion Revisited: Group Dynamics and Group Psychotherapy'. In M. Pines (ed) Bion and Group Psychotherapy. London: Routledge and Kegan Paul.

Swan, J., Scarborough, H., and Robertson, M. (2002) 'The Construction of "Communities of Practice" in the Management of Innovation'. Management Learning, 33(4): 477-496.

Tönnies F. (1887/1963) Community and society, New York: Harper Torchbook. 
Turquet, PM. (1974) Leadership: The individual and the group. In: Gibbard G, Hartman J and Mann R (eds) Analysis in Groups. San Francisco: Jossey-Bass, 378-397.

Wenger, E., McDermott, R. and Snyder, W.M. (2002) Cultivating communities of practice: Guide to managing knowledge. Boston: MA: Harvard Business School Press.

Wenger, E. and Snyder, W.M. (2000) 'Communities of Practice: The Organizational Frontier', Harvard Business Review. January-February. 139-145.

Wenger, E. (1998) Communities of Practice: Learning, Meaning and Identity. Cambridge: Cambridge University Press.

Wenger, E. (2011) Communities of practice: A brief introduction.

Weingart, L.R. (2015) 'Studying Dynamics within Groups'. In Margaret A. Neale, Elizabeth A. Mannix (ed.) Looking Back, Moving Forward: A Review of Group and Team-Based Research (Research on Managing Groups and Teams, Volume 15). Bingley: Emerald Group Publishing Limited, pp. $1-25$.

Young, I.M. (1986) 'The ideal of community and the politics of difference'. Social Theory and Practice, 12(1), 1-26. 